\title{
Necrotizing Enterocolitis in Preterm Infants Born to Mother with COVID-19
}

\author{
Dina Angelika ${ }^{1,2^{*}}$, Risa Etika ${ }^{2}$, Angelica Diana Vita ${ }^{3}$, Setya Mirtha ${ }^{4}$, I Dewa Gede Ugrasena ${ }^{2}$ \\ ${ }^{1}$ Postgraduate Doctoral Program, Faculty of Medicine Universitas Airlangga, Surabaya, Indonesia; ${ }^{2}$ Department of Pediatrics, \\ Faculty of Medicine Universitas Airlangga, Surabaya, Indonesia; ${ }^{3}$ Medical Study Program, Faculty of Medicine Universitas \\ Airlangga, Surabaya, Indonesia; ${ }^{4}$ Department of Pediatrics, Faculty of Medicine Brawijaya University, Malang, Indonesia
}

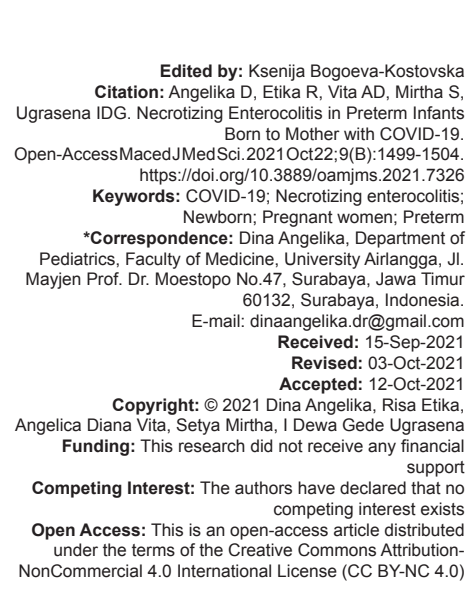

\section{Introduction}

Since the COVID-19 infection was first discovered in China at the end of 2019, COVID-19 has become increasingly widespread throughout the world, up to Indonesia [1], [2]. Developing countries, including Indonesia, have been affected by the COVID-19 pandemic, which has led to increased morbidity in pregnant women and adverse outcomes for newborns [3], [4]. Data from the Ministry of Health of the Republic of Indonesia demonstrate that to date, more than 2 million Indonesians have been infected with COVID-19 with a death rate of more than 70,000 people [4], [5]. The Indonesian Obstetrics Doctors Association reports that more than 500 pregnant women in Indonesia have been infected with COVID-19 with mortality rate of $20 \%$ [6], [7].

\section{Abstract}

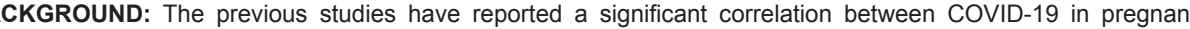
women with the incidence of pre-eclampsia and HELLP syndrome. Pre-eclampsia is known to be a risk factor for AIM: This study aimed to investigate the incidence and associated factor of NEC in preterm infants born to mothers with COVID-19.

ODS: This observational study was conducted in neonatal intensive care unit at Dr. Soetomo General Academic Hospital, Surabaya, Indonesia. Data collection was carried out from May 2020 to April 2021. All preterm infants born to mothers with positive COVID-19 were included as study participants. Infants were excluded if their parents did not provide consent. Of the 49 preterm infants born to mother with COVID-19, one infant had the SARS-CoV-2 virus could be detected on a nasal swab and throat swab through the reverse transcription-PCR The diagnosis of NEC was established by clinical symptoms and confirmed by abdominal radiography. ince asphyxia (odds ratio $[\mathrm{OR}]=10.000,95 \%$ confidence interval $[\mathrm{Cl}]=1.056-94.677, \mathrm{p}=0.020$ ) and intubated significantly increase the risk of NEC. The combination of positive PCR result with asphyxia and intubated mothe

CONCLUSIONS: This study found that $13.3 \%$ of preterm infants born to mother with COVID-19 experienced NEC. Significant factors associated with the incidence of NEC in preterm infants born to mothers with COVID-19 included asphyxia and intubated mothers before delivery. A positive PCR result alone did not significantly increase the risk of NEC. Further research is needed to investigate other factors in NEC preterm infants born to COVID-19 mothers.
Necrotizing enterocolitis (NEC), which is characterized by intestinal necrosis and inflammation, is the most common gastrointestinal emergency in preterm infants and often requires surgery intervention [8]. NEC morbidity and mortality are still high. Mortality rates may reach $20-45 \%$ and can be even higher in developing countries. This makes NEC the leading cause of death in premature infants [9]. Infants who survive NEC may experience sequelae, including short bowel syndrome, failure to thrive, and neurodevelopmental disorders [8].

The previous studies have demonstrated a significant association between COVID-19 in pregnant women with the incidence of pre-eclampsia and HELLP syndrome [10]. Pre-eclampsia is a known risk factor for NEC [11]. Since the COVID-19 pandemic has had a wide impact on both pregnant women and their babies, the incidence of NEC in preterm infants born to mothers with confirmed COVID-19 is not clearly known 
to date. Therefore, this study aimed to investigate the incidence of NEC in preterm infants born to mothers with confirmed COVID-19.

\section{Materials and Methods}

\section{Study design and ethical approval}

This observational study was conducted in neonatal intensive care unit (NICU) at Dr. Soetomo General Academic Hospital, Surabaya, Indonesia. Data collection was carried out from May 2020 to April 2021. This study was approved by the Ethical Committee in Health Research at the Dr. Soetomo General Academic Hospital, Surabaya (Reference no. 0084/KEPK/X/2020). Informed and signed consent was acquired from the parents or authorized representatives of each infant.

\section{Participants}

All preterm infants born to mothers with positive COVID-19 were included as study participants. Infants were excluded if they had multiple congenital anomalies, spontaneous intestinal perforation was established during surgery, and their parents did not provide consent. Of the 164 infants born to COVID19 mothers during the study period, 115 infants were born at term and 49 infants were premature. Of the 49 preterm infants, one infant had multiple congenital anomalies and three infants did not get parental consent. No infants had spontaneous intestinal perforation. Therefore, a total of 45 preterm infants were analyzed in this study. According to the protocol at our hospital, all infants born to mothers who confirmed positive COVID-19 were performed for swab examination within $48 \mathrm{~h}$ after birth. All infants were cared for in the NICU isolation room. Enteral nutrition was administered using a combination of expressed human milk and premature infant formula.

\section{Diagnosis of COVID-19}

The diagnosis of COVID-19 was confirmed positive when the SARS-CoV-2 virus could be detected on a nasal swab and throat swab through the reverse transcription-polymerase chain reaction (PCR) examination (Abbot, Des Plaines, United States). The Government of Indonesia stipulated the organization of the COVID-19 examination laboratory based on the Decree of the Minister of Health of the Republic of Indonesia Number HK.01.07/Menkes/4642/2021, including the diagnostic laboratory at Dr. Soetomo Hospital. PCR swab examination was performed within $48 \mathrm{~h}$ after birth. The diagnosis of COVID-19 was defined as positive if the swab test result could detect the SARS-CoV-2 virus [12].

\section{NEC}

The diagnosis of NEC was established by clinical symptoms (at least one of the following symptoms: Increased gastric residual before feeding more than $20 \%$ of feeding volume, marked abdominal distension, emesis, abdominal tenderness, and guaiacpositive stool) and confirmed by abdominal radiography (at least one of the following results: lleus, persistent bowel loop, pneumatosis intestinalis, portal venous gas, and pneumoperitoneum) [13]. If focal perforation of the gastrointestinal tract was found at the time of surgery, the infant included spontaneous intestinal perforation and was excluded from this study [14].

\section{Asphyxia}

Asphyxia is defined as failure to initiate breathing or maintain normal breathing in newborns at birth. Asphyxia was confirmed by an Apgar score of $>5$ at 5 min [15]. Respiratory failures in mothers due to COVID-19 have contributed to asphyxia [16]. In this study, maternal respiratory failure was described with intubated mothers. Intubated mothers were defined as mothers who had been intubated before or during delivery due to maternal respiratory failure.

\section{Data analysis and statistical analysis}

Quantitative data were described using mean, range, and standard deviation (SD). Qualitative data were described using frequencies and percentages. The variables analyzed included the characteristics of the infants (sex, birth weight, gestational age, mode of delivery, multiple birth, COVID-19 PCR swab result, NEC, death, and asphyxia) and the mothers (age, intubated mother, and comorbid).

This study analyzed the determinant factors associated with the incidence of NEC including sex, birth weight, gestational age, mode of delivery, mother's age $\geq 35$ years, death, positive PCR result, asphyxia, intubated mother, combination asphyxia with intubated mother, and also combination of asphyxia, intubated mother, and positive PCR results. Factors associated with the incidence of NEC were analyzed using the Chisquared test. All statistical analyses were performed using IBM SPSS Statistics 21 (IBM Corp., Armonk, NY, USA). $p<0.05$ was considered statistically significant.

\section{Results}

\section{Characteristics of participants}

Of the 45 preterm infants included, the birth weight ranged from 900 to $2498 \mathrm{~g}$ (2083.7 \pm 416.3), whereas the gestational age ranged from 28 to 36 weeks 
(mean $\pm \mathrm{SD} ; 33.8 \pm 2.2$ ). The majority of infants' birth weight $(88.9 \%)$ were low birth weight $(1500-<2500 \mathrm{~g})$ and the majority of infants' gestational age (60\%) were late preterm (34-<37 weeks). The majority of infants $(68.9 \%)$ were delivered by cesarean section. Based on the swab examination at birth, as many as $5(11.1 \%)$ infants born had positive PCR results for COVID19. The mother's age ranged from 17 to 43 years old $(28.9 \pm 6.1)$, most of the mothers $(73.4 \%)$ were aged $21-<35$ years old. The majority of mother's comorbid $(62.2 \%)$ in this study were pre-eclampsia. The detail characteristics of all infants are described in Table 1.

Table 1: Characteristics of all participants $(n=45)$

\begin{tabular}{ll}
\hline Variable & $\mathrm{n}(\%)$ \\
\hline Sex & \\
Male & $26(57.8)$ \\
Female & $19(42.2)$ \\
Birth weight (g) & \\
1500-<2500 & $40(88.9)$ \\
$1000-<1500$ & $4(8.9)$ \\
<1000 & $1(2.2)$ \\
Gestational age (weeks) & \\
34-<37 & $27(60)$ \\
$32-<34$ & $12(26.7)$ \\
$28-<32$ & $6(13.3)$ \\
Mode of delivery & \\
Spontaneous & $14(31.1)$ \\
Cesarean section & $31(68.9)$ \\
Multiple birth & $1(2.2)$ \\
COVID-19 PCR swab result & \\
Positive & $5(11.1)$ \\
Negative & $40(88.9)$ \\
NEC & \\
Yes & $6(13.3)$ \\
No & $39(86.7)$ \\
Outcome & \\
Death & $6(13.3)$ \\
Survive & $39(86.7)$ \\
Asphyxia & \\
Yes & $18(40)$ \\
No & $27(60)$ \\
Intubated mother & \\
Yes & $3(6.7)$ \\
No & $42(93.3)$ \\
Asphyxia+intubated mother & \\
Yes & $18(40)$ \\
No & $27(60)$ \\
Positive PCR results+asphyxia+intubated mother & \\
Yes & $22(48.9)$ \\
No & $23(51.1)$ \\
Mother's age (years old) & \\
$\geq 35$ & $10(22.2)$ \\
$21-<35$ & $33(73.4)$ \\
$<21$ & $2(4.4)$ \\
Mother's comorbid other than CovID-19 \\
Pre-eclampsia \\
Hypertension \\
Premature rupture of membrane & $28(62.2)$ \\
\hline p<0.05 was considered statistically significant. PCR: Polymerase chain reaction. \\
$\quad 8(17.8)$ \\
\hline
\end{tabular}

\section{Characteristics of preterm infants with}

\section{NEC}

In this study, there were $6(13.3 \%)$ preterm infants with NEC. Table 2 describes the characteristics of the six preterm infants who developed NEC in this study. The birth weight ranged from 900 to $1770 \mathrm{~g}$ (1377.5 \pm 310.8), whereas the gestational age ranged from 28 to 33 weeks $(30 \pm 2.1)$. The majority of infants' birth weight $(50 \%)$ were low birth weight $(1500-<2500 \mathrm{~g})$ and the majority of infants' gestational age $(66.7 \%)$ were $28-\leq 32$ weeks. The majority of these preterm infants $(66.7 \%)$ were delivered by cesarean section. Of the five preterm infants who had asphyxia, there were two infants whose mothers were intubated before delivery. The onset of symptoms occurred within the first 2 weeks after birth. Five of the six preterm infants who developed NEC in this study died.

\section{Determinant factors associated with the incidence of NEC}

There were significant differences between with and without NEC on birth weight and gestational age. However, no significant differences were found with and without NEC with regard to sex, mode of delivery, positive PCR result, and mother's age $\geq 35$ years old. Factors that were significantly associated with the incidence of NEC included asphyxia (odds ratio $[\mathrm{OR}]=10.000,95 \%$ confidence interval $[\mathrm{Cl}]=1.056-94.677, \mathrm{p}=0.020)$ and intubated mother $(\mathrm{OR}=19.000,95 \% \mathrm{Cl}=1.394-258.954$, $\mathrm{p}=0.005)$. However, a positive PCR results from the infants alone did not significantly increase the risk of NEC. This study found that the combination of asphyxia and intubated mother (OR $=10.000,95 \%$ $\mathrm{Cl}=1.056-94.677, \mathrm{p}=0.020)$ and the combination of positive PCR result with asphyxia and intubated mother $(\mathrm{OR}=2.438,95 \% \mathrm{Cl}=1.673-3.551, \mathrm{p}=0.007)$ were found to be significantly associated with the incidence of NEC (Table 3 ).

\section{Discussion}

Since the end of 2019, the COVID-19 pandemic has caused a lot of morbidity and mortality in many countries, including Indonesia. At the beginning of the pandemic, the elderly group was a group that was vulnerable to COVID-19 infection. As the disease progresses, pregnant women become a group at risk for complications of COVID-19 infection. COVID-19 infection causes disruption of the placental vascular system of pregnant women, thus affecting the fetoplacental unit. The previous studies have demonstrated that pregnant women with complications of COVID-19 show symptoms of pre-eclampsia and the HELLP syndrome [17]. Pre-eclampsia, as a maternal antenatal factor, will increase the risk of NEC in neonates [18]. This study demonstrated that pregnant women with confirmed COVID-19 had a significant association with the occurrence of NEC in preterm infants.

Compared to pregnant women without COVID-19, pregnant women with confirmed COVID-19 were significantly more likely to have premature births [19]. A study conducted by Ayed et al. [16] who showed that most infants $(73.3 \%)$ born to COVID-19 positive mothers were term and most had a birth weight of more than $2500 \mathrm{~g}$. Another study by Anand et al. [20] showed that premature births to COVID-19 positive mothers tended to be more numerous than 
Table 2: Characteristics of six preterm infants with NEC

\begin{tabular}{|c|c|c|c|c|c|c|}
\hline Variable & Sample \#1 & Sample \#2 & Sample \#3 & Sample \#4 & Sample \#5 & Sample \#6 \\
\hline Sex & $\mathrm{F}$ & $\mathrm{F}$ & $\mathrm{M}$ & $\mathrm{M}$ & $\mathrm{F}$ & $\mathrm{M}$ \\
\hline BW (g) & 1770 & 1600 & 1300 & 1490 & 1200 & 900 \\
\hline GA (weeks) & 33 & 33 & 32 & 30 & 28 & 28 \\
\hline Symptom onset (day after birth) & Day 8 & Day 6 & Day 6 & Day 6 & Day 6 & Day 5 \\
\hline Mode of delivery & Spontaneous & CS & CS & cS & cs & Spontaneous \\
\hline Positive PCR result & Yes & No & Yes & No & No & No \\
\hline Asphyxia & No & Yes & Yes & Yes & Yes & Yes \\
\hline Intubated mother & No & No & Yes & No & No & Yes \\
\hline Death & No & Yes & Yes & Yes & Yes & Yes \\
\hline Mother age $\geq 35 \mathrm{y}$ & No & Yes & Yes & No & No & Yes \\
\hline
\end{tabular}

full-term births ( $51 \%$ vs. $49 \%)$. The results of this study demonstrated that the majority of preterm infants born to mothers who confirmed COVID-19 had a gestational age of $34-<37$ weeks $(60 \%)$ and a birth weight of $1500-<2500 \mathrm{~g}(88.9 \%)$. Other studies that describe the detailed characteristics of preterm infants born to COVID-19 positive mothers are still limited.

The majority of infants in this study were born by cesarean section. The previous studies reported that most of the methods of delivery for pregnant women who were positive for COVID-19 were by cesarean section [21]. Another study reported that the method of delivery by cesarean section was found to increase by 3 times or more in pregnant women with COVID-19 compared to women without COVID-19. Indications for cesarean delivery were respiratory difficulties in the mother apart from other obstetric comorbidities [19].

In this study, six preterm infants experienced NEC. The onset of clinical symptoms in this study ranged from the first $5-8$ days after birth. The diagnosis of NEC is based on a combination of clinical signs and abnormal findings on plain abdominal radiographs [22]. Clinically, the presentation of NEC appears within 2 weeks after birth [23].

Factors that were significantly associated with the incidence of NEC in this study included asphyxia and intubated mothers before delivery. Although the previous studies reported poor outcomes in neonates born to COVID-19 mothers, the incidence of NEC in these infants varied widely [19]. The study by Norman et al. showed that $<5 \%$ of neonates born to COVID-19 mothers had NEC, of which perinatal asphyxia occurred in $2 \%$ [24]. Another study showed that no NEC was found in neonates born to COVID-19 mothers in which the neonates had good Apgar scores [19] A study conducted by Yaman et al. who showed that feeding intolerance is a common clinical symptom in neonates with COVID, which these gastrointestinal symptoms are associated with premature infants [25]. The severity of the COVID-19-positive pregnant woman is related to the condition of the newborn being born. About $20 \%$ of newborns born to COVID-positive mothers who have severe respiratory problems requiring intubation require resuscitation at birth [26]. The practice of using preterm formula may present a risk of NEC [22]. However, in this study, all preterm infants analyzed were using preterm formula.

This study found that about $11.1 \%$ of infants born have positive COVID-19 PCR results. Similar results were reported by other studies [20], [27]. The intrauterine transmission of COVID-19 infection is still a matter of debate. However, recent studies have shown that there are vascular abnormalities and signs of acute chorioamnionitis from the placenta of infants born to COVID-19-positive mothers [28]. This could be an explanation of the results of this study which showed that a positive PCR result alone did not significantly increase the risk of NEC although the combination of a positive PCR result with asphyxia and intubated mothers significantly increased the risk of NEC. The incidence of NEC was also significantly associated with mortality. The cause of mortality in these NEC cases is possible because all cases of NEC in this study

Table 3: Factors associated with the incidence of NEC

\begin{tabular}{|c|c|c|c|c|c|}
\hline Variable & $\mathrm{NEC} n=6 \mathrm{n}(\%)$ & No NEC $n=39 n(\%)$ & OR & $95 \% \mathrm{Cl}$ & $\mathrm{p}$ \\
\hline Sex & & & NA & NA & 0.679 \\
\hline Male & $3(50)$ & $23(58.9)$ & & & \\
\hline Female & $3(50)$ & $16(41.1)$ & & & \\
\hline Birth weight (g) & & & NA & NA & $0.002^{*}$ \\
\hline $1500-<2500$ & $3(50)$ & $37(94.9)$ & & & \\
\hline $1000-<1500$ & $2(33.3)$ & $2(5.1)$ & & & \\
\hline$<1000$ & $1(16.7)$ & $0(0)$ & & & \\
\hline Gestational age (weeks) & & & NA & NA & $<0.001^{*}$ \\
\hline $34-<37$ & $0(0)$ & $27(69.2)$ & & & \\
\hline $32-<34$ & $2(33.3)$ & $10(25.7)$ & & & \\
\hline $28-<32$ & $4(66.7)$ & $2(5.1)$ & & & \\
\hline Mode of delivery & & & NA & NA & 0.899 \\
\hline Spontaneous & $2(33.3)$ & $12(30.8)$ & & & \\
\hline Cesarean section & $4(66.7)$ & $27(69.2)$ & & & \\
\hline Positive PCR result & $2(33.3)$ & $3(7.7)$ & 6.000 & $0.760-47.358$ & 0.063 \\
\hline Asphyxia & $5(83.3)$ & $13(33.3)$ & 10.000 & $1.056-94.677$ & $0.020^{*}$ \\
\hline Intubated mother & $2(33.3)$ & $1(2.6)$ & 19.000 & $1.394-258.954$ & $0.005^{*}$ \\
\hline Asphyxia+intubated mother & $5(83.3)$ & $13(33.3)$ & 10.000 & $1.056-94.677$ & $0.020^{*}$ \\
\hline Positive PCR result+asphyxia+intubated mother & $6(100)$ & $16(41.0)$ & 2.438 & $1.673-3.551$ & $0.007^{\star}$ \\
\hline Death & $5(83.3)$ & $0(0)$ & 0.167 & $0.028-0.997$ & $<0.001^{*}$ \\
\hline Mother's age 35 years & $3(50)$ & $7(17.9)$ & 4.571 & $0.758-27.577$ & 0.079 \\
\hline
\end{tabular}


occurred in premature infants and/or in low birth weight infants [29].

This study had several limitations that need to be considered. First, our sample size was relatively small. Although this was a small group study, COVID-19 was a novel infection and similar research was still limited, so the results of this study could be taken into consideration. Second, this study was conducted during the first wave of COVID-19 infection in Indonesia, where the conditions could be different in the second wave. Further multicenter studies need to be carried out on the second wave of COVID-19 infections.

\section{Conclusions}

This study indicated that COVID-19 infection in pregnancy had a contribution to the incidence of NEC in preterm infants. As many as, $13.3 \%$ of preterm infants born to mother with COVID-19 experienced NEC. Significant factors associated with the incidence of NEC in preterm infants born to mothers with COVID-19 included asphyxia and intubated mothers prior to delivery. A positive PCR result alone did not significantly increase the risk of NEC. A strong association was found between the incidence of NEC in preterm infants born to mother with COVID-19 and mortality. Studies of longterm development of preterm infants born to mothers with COVID-19 are warranted. Moreover, further research is now needed to investigate other factors in NEC preterm infants born to COVID-19 mothers.

\section{Acknowledgment}

The authors would like to thank all staff in the Neonatology Division, Pediatric Ward, and the nurses at Dr. Soetomo General Academic Hospital for the support of this research.

\section{References}

1. Telles CR, Roy A, Ajmal MR, Mustafa SK, Ahmad MA de la Serna JM, et al. The impact of COVID-19 management policies tailored to airborne SARS-CoV-2 transmission: Policy analysis. JMIR Public Health Surveill. 2021;7(4):e20699. http:// doi.org/10.2196/20699

PMid:33729168

2. Khalid MS, Aljohani MM, Oyouni NA, Alzahrani O, Ahmad MA, Al-Aoh HA, et al. COVID-19 and immune function a-significant zinc. Orient J Chem. 2020;36(6):1026-36. http://doi. org/10.13005/ojc/360604
3. Mustafa SK, Ahmad MA, Baranova V, Deineko Z, Lyashenko V, Oyouni AA. Using wavelet analysis to assess the impact of COVID-19 on changes in the price of basic energy resources. Int J Emerg Trends Eng Res. 2020;8(7):2907-12. https://doi. org/10.30534/ijeter/2020/04872020

4. Kementerian Kesehatan RI. Situasi Terkini Perkembangan Coronavirus Disease. Available from: https://covid19.kemkes. go.id/document/situasi-terkini-perkembangan-coronavirusdisease-covid-19-18-juli-2021/view [Last accessed on 2021 Jul 18].

5. Mustafa SK, Ahmad MA, Sotnik S, Zeleniy O, Lyashenko V, Alzahrani $O$. Brief review of the mathematical models for analyzing and forecasting transmission of COVID-19. J Crit Rev. 2020;7(19):4206-10. https://doi.org/10.31838/jcr.07.19.493

6. Khalid MS, Lyashenko V, Ahmad NA, Ajmal MR, Ahmad MA. Some aspects of modeling in the study of COVID-19 data. Int J Pharm Res. 2021;13(1):4124-9. http://doi.org/10.31838/ ijpr/2021.13.01.586

7. CNN Indonesia. POGI: 20 Persen Kematian ibu Hamil Akibat Positif COVID-19. Available from: https://www.cnnindonesia. com/nasional/20210819110357-20-682327/pogi-20-persenkematian-ibu-hamil-akibat-positif-covid-19 [Last accessed on 2021 Aug 18].

8. Yikilmaz A, Hall NJ, Daneman A, Gerstle JT, Navarro OM, Moineddin R, et al. Prospective evaluation of the impact of sonography on the management and surgical intervention of neonates with necrotizing enterocolitis. Korean $\mathrm{J}$ Pediatr. 2014;57(8):351-6.

9. Zozaya C, Gonzalez IG, Avila-Alvarez A, Oikonomopoulou N, Tamayo TS, Salguero E, et al. Incidence, treatment, and outcome trends of necrotizing enterocolitis in preterm infants: A multicenter cohort study. Front Pediatr. 2020;8:188. http://doi. org/10.3389/fped.2020.00188 PMid:32478014

10. Conde-Agudelo A, Romero R. SARS-CoV-2 infection during pregnancy and risk of preeclampsia: A systematic review and meta-analysis. Am J Obstet Gynecol. 2021;2021:00795.

PMid:34302772

11. Perger L, Mukhopadhyay D, Komidar L, Wiggins-Dohlvik K, Uddin MN, Beeram M. Maternal pre-eclampsia as a risk factor for necrotizing enterocolitis. Matern Fetal Neonatal Med. 2016;29(13):2098-103.

PMid:27480208

12. Trevisanuto D, Weiner G, Lakshminrusimha S, Azzimonti G, Nsubuga JB, Velaphi $\mathrm{S}$, et al. Management of mothers and neonates in low resources setting during covid-19 pandemia. J Matern Fetal Neonatal Med. 2020;2020:1-12. http://doi.org/10 $.1080 / 14767058.2020 .1784873$

PMid:32602386

13. Gregory KE, Deforge CE, Natale KM, Phillips M, Van Marter LJ Necrotizing enterocolitis in the premature infant: Neonatal nursing assessment, disease pathogenesis, and clinical presentation. Adv Neonatal Care. 2011;11(3):155-64; quiz 165-6. http://doi.org/10.1097/ANC.0b013e31821baaf4 PMid:21730907

14. Stout G, Lambert DK, Baer VL, Gordon PV, Henry E, Wiedmeier SE, et al. Necrotizing enterocolitis during the first week of life: A multicentered case-control and cohort comparison study. J Perinatol. 2008;28(8):556-60. http://doi.org/10.1038/ jp.2008.36 PMid: 18368057

15. Zhong YJ, Claveau M, Yoon EW, Azziz K, Singhal N, Shah PS, et al. Neonates with a 10-min Apgar score of zero: Outcomes by gestational age. Resuscitation. 2019;143:77-84. http://doi. org/10.1016/j.resuscitation.2019.07.036

PMid:31421194 
16. Ayed A, Embaireeg A, Benawadh A, Al-Fouzan W, Hammoud M, Al-Hathal $\mathrm{M}$, et al. Maternal and perinatal characteristics and outcomes of pregnancies complicated with COVID-19 in Kuwait. BMC Pregnancy Childbirth. 2020;20(1):754.

PMid:33267785

17. Hcini N, Maamri F, Picone O, Carod JF, Lambert V, Mathieu M, et al. Maternal, fetal and neonatal outcomes of large series of SARS-CoV-2 positive pregnancies in peripartum period: A single-center prospective comparative study. Eur J Obstet Gynecol Reprod Biol. 2021;257:11-8. http://doi.org/10.1016/j. ejogrb.2020.11.068

PMid:33310656

18. Duci M, Frigo AC, Visentin S, Verlato G, Gamba $P$, Fascetti-Leon F. Maternal and placental risk factors associated with the development of necrotizing enterocolitis (NEC) and its severity. J Pediatr Surg. 2019;54(10):2099-102. http://doi. org/10.1016/j.jpedsurg.2019.04.018 PMid:31084912

19. Yang R, Mei H, Zheng T, Fu Q, Zhang Y, Buka S, et al. Pregnant women with COVID-19 and risk of adverse birth outcomes and maternal-fetal vertical transmission: A population-based cohort study in Wuhan, China. BMC Med. 2020;18(1):330. PMid:33070775

20. Anand P, Yadav A, Debata P, Bachani S, Gupta N, Gera R. Clinical profile, viral load, management and outcome of neonates born to COVID 19 positive mothers: A tertiary care centre experience from India. Eur J Pediatr. 2021;180(2):547-59. http:// doi.org/10.1007/s00431-020-03800-7 PMid:32910210

21. Brandt JS, Hill J, Reddy A, Schuster M, Patrick HS, Rosen T, et al. Epidemiology of coronavirus disease 2019 in pregnancy: Risk factors and associations with adverse maternal and neonatal outcomes. Am J Obstet Gynecol. 2021;224(4):389. e1-9. http://doi.org/10.1016/j.ajog.2020.09.043 PMid:32986989

22. Rasiah V, Yajamanyam PK, Ewer AK. Necrotizing enterocolitis: Current perspectives. Res Reports Neonatol. 2014;4:31-42.

23. Yee WH, Soraisham AS, Shah VS, Aziz K, Yoon W, Lee SK, et al.
Incidence and timing of presentation of necrotizing enterocolitis in preterm infants. Pediatrics. 2012;129(2):e298-304. http://doi. org/10.1542/peds.2011-2022

PMid:22271701

24. Norman M, Naver L, Soderling J, Ahlberg M, Hervius $H$, Aronsson B, et al. Association of maternal SARS-CoV-2 infection in pregnancy with neonatal outcomes. JAMA. 2021;325(20):2076-86. http://doi.org/10.1001/jama.2021.5775 PMid:33914014

25. Yaman A, Kandemir I, Varkal MA. Infants infected with SARS-CoV-2 and newborns born to mother diagnosed with COVID-19: Clinical experience. Ir J Med Sci. 2021;2021:1-6. http://doi.org/10.1007/s11845-021-02662-8

PMid:34075529

26. Dumitriu D, Emeruwa UN, Hanft E, Liao GV, Ludwig E, Walzer L, et al. Outcomes of neonates born to mothers with severe acute respiratory syndrome coronavirus 2 infection at a large medical center in New York City. JAMA Pediatr. 2021;175(2):157-67. http://doi.org/10.1001/jamapediatrics.2020.4298

PMid:33044493

27. Chi H, Chiu NC, Tai YL, Chang HY, Lin CH, Sung YH, et al Clinical features of neonates born to mothers with coronavirus disease-2019: A systematic review of 105 neonates. J Microbiol Immunol Infect. 2021;54(1):69-76. http://doi.org/10.1016/j. jmii.2020.07.024

PMid:32847748

28. Patberg ET, Adams T, Rekamek P, Vahanian SA, Akerman M, Hernandez A, et al. Coronavirus disease 2019 infection and placental histopathology in women delivering at term. Am J Obstet Gynecol. 2021;224(4):382.e1-18. http://doi. org/10.1016/j.ajog.2020.10.020

PMid:33091406

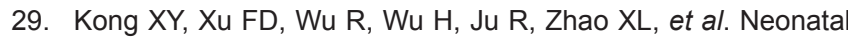
mortality and morbidity among infants between 24 to 31 complete weeks: A multicenter survey in China from 2013 to 2014. BMC Pediatr. 2016;16(1):174. http://doi.org/10.1186/ s12887-016-0716-5

PMid:27809893 